\title{
The Effects of Grain Size and Precipitate on \\ Strength of Nb-Treated Steels*
}

\author{
By Yünoshin IMAI $I^{* *}$ and Yoshio SHŌNO ${ }^{* * *}$
}

\begin{abstract}
Synopsis
Relationship between the strength and the change in grain size and precipitation behavior of $\mathrm{NbC}$ due to heat treatments was examined with $0.2 \%$ carbon steels containing 0.02 to $0.09 \%$ niobium. The results are summarized as follows.

(1) Though $\mathrm{NbC}$ particles precipitated in niobium-treated steels tend to coalesce with the rise of austenitizing temperature, they remain in steel and prevent the austenite grain from coarsening because of its small solubility and low dissolving rate in austenite.

(2) The highest strength is obtained when the cooling rate from austenitizing temperature to room temperature is $25^{\circ} \mathrm{C} / \mathrm{min}$. When niobium-treated steel is continuously cooled afler a full solution treatment for a long time at sufficiently high temperatures such as $1250^{\circ} \mathrm{C}, \mathrm{NbC}$ seems to precipitate not only at temperatures lower than $A_{3}$ point but also at temperatures of austenite range, and this precipitation from austenite will cause less strengthening than that from ferrite.

(3) Strengthening effect by niobium-treatment may be explained on the assumption that both effects of the grain refinement and the precipitation of fine particles of $\mathrm{NbC}$ are additive to each other. An increase of strength in niobium-treated steels austenitized at temperatures lower than about $1050^{\circ} \mathrm{C}$ is due mainly to refining of ferrite grain and that at higher temperatures is due mainly to fine precipitates of $\mathrm{NbC}$.
\end{abstract}

\section{Introduction}

It is well known that the addition of a small amount of niobium to carbon steels or low alloy steels causes the grain refinement and the improvement of strength and toughness, ${ }^{1)-3}$ ) as in the case of titanium, vanadium, zirconium, or aluminium addition. Recently, the precipitation strengthening effect of niobium compound (carbide or carbonitride) is being brought to attention, ${ }^{4)-7)}$ as the strength of niobium-treated steels considerably varies with heat treatment. Though the characteristics of niobium-treated steels have been studied fairly well, ${ }^{8), 9)}$ the strengthening mechanism has not been thoroughly confirmed yet because of their multiple controlling factors. It is conceived that effects of the elements other than niobium may be much complicated to be separated from each other when commercial steels are used for specimens, and that a change in the quantity of niobium dissolved into matrix in practical heat treatments has not been elucidated. Besides, the relationship between strengthening by grain refinement and that by precipitation has not been sufficiently examined.

In the present experiment with $0.2 \%$ carbon steels containing 0.02 to $0.09 \%$ niobium, the solubility in austenite and the precipitation behavior of $\mathrm{NbC}$ were studied to clarify the strengthening effects of grain refinement and precipitation in niobium-treated steels; the relationship between grain size and precipitation and yield strength was examined by changing austenitizing temperature and subsequent cooling rate.

\section{Experimental Procedure}

Carbon steels and 0.02 to $0.09 \%$ niobium-treated steels were prepared with electrolytic iron, high-purity carbon, and pure niobium by vacuum induction melting. The chemical analyses of steels are given in Table 1. Each steel was forged and rolled at 950 to $1050^{\circ} \mathrm{C}$ to bar $6 \mathrm{~mm}$ in diameter and to sheet $2.5 \mathrm{~mm}$ in thickness. Besides, compounds, NbC and $\mathrm{NbN}$, were prepared as standard specimens for X-ray analysis by carburizing or nitriding pure niobium sheet melted by electron beam.

Austenitizing temperature was varied in the range of $925^{\circ}$ to $1200^{\circ} \mathrm{C}$ (in some cases $1100^{\circ}$ to $1350^{\circ} \mathrm{C}$ ) and subsequent average cooling rates, such as $50^{\circ} \mathrm{C}$ / hr (very slow cooling), $100^{\circ} \mathrm{C} / \mathrm{min}$ (annealing), and $1000^{\circ} \mathrm{C} / \mathrm{min}$ (normalizing), were assigned, to examine the change in the amount of niobium dissolved in austenite, NbC precipitate condition, and grain size of austenite and ferrite.

At room temperature, tensile test was carried out with Instron machine at the strain rate of $6.4 \times 10^{-4}$ sec, the specimen being $3 \mathrm{~mm}$ in diameter and $11 \mathrm{~mm}$ in gauge length, and the Vickers hardness was also measured. The effect of cooling rate on the strength was examined in detail by measuring the micro Vickers hardness of ferrite in specimens which were continuously cooled at various rates of $5^{\circ}$ to $1000^{\circ} \mathrm{C} / \mathrm{min}$ controlled accurately by automatic induction heating apparatus. In addition, $\mathrm{NbC}$ precipitation from austenite was examined by hardness measurement of niobium-treated steel NC90 (Table 1) which was cooled at various rates of $1^{\circ}$ to $2400^{\circ} \mathrm{C} / \mathrm{min}$ from $1250^{\circ}$ to $850^{\circ} \mathrm{C}$, then quenched, and tempered at $650^{\circ} \mathrm{C}$ for $1 \mathrm{hr}$.

Austenite grain size was measured by instantaneous oxidation method ${ }^{10)}$ and/or vacuum etching method, and after cooling ferrite grain size was also measured in accordance with JIS method.

Niobium-treated steel NC91 water-quenched at $925^{\circ} \mathrm{C}$ was subjected to electrolytic extraction in $0.5 \mathrm{~N}$ $\mathrm{HCl}$. Then the extracted residue was identified by $\mathrm{X}$-ray diffraction with $\mathrm{Cu}-\mathrm{K}_{\alpha}$ radiation using DebyeScherrer camera and the lattice constant was deter-

* Originally published in Tetsu-to-Hagané, 54 (1968), 1343 in Japa-nese. Manuscript received December $23,1968$.

** The Research Institute for Iron, Steel and Other Metals, Tohoku University, Katahira-cho, Sendai, 980.

*** Graduate School, Tohoku University, Aramaki, Sendai, 980. 
Table 1. Chemical compositions of specimens (as cast)

(A) Carbon steels

\begin{tabular}{|c|c|c|c|c|c|c|c|c|c|}
\hline \multirow{2}{*}{ Mark } & \multirow{2}{*}{$\mathrm{C}$} & \multirow{2}{*}{$\mathrm{Si}$} & \multirow{2}{*}{$\mathrm{Mn}$} & \multirow{2}{*}{$\mathrm{P}$} & \multirow{2}{*}{$\mathrm{S}$} & \multicolumn{3}{|c|}{$\mathrm{N}$} & \multirow{2}{*}{$\mathrm{O}$} \\
\hline & & & & & & Sol. & Insol. & (Tot.) & \\
\hline FC 22 & 0.22 & 0.016 & 0.001 & 0.002 & 0.008 & 0.002 & 0.001 & 0.003 & 0.0020 \\
\hline FC 21 & 0.21 & & & & & & & & \\
\hline
\end{tabular}

(B) Nb-treated steels

\begin{tabular}{|c|c|c|c|c|c|c|c|c|}
\hline \multirow{2}{*}{ Mark } & \multirow{2}{*}{ C } & \multicolumn{3}{|c|}{$\mathrm{Nb}$} & \multicolumn{3}{|c|}{$\mathrm{N}$} & \multirow{2}{*}{$\mathrm{O}$} \\
\hline & & Sol. & Insol. & (Tot.) & Sol. & Insol. & (Tot.) & \\
\hline NC 25 & 0.17 & 0.023 & 0.002 & 0.025 & 0.005 & 0.001 & 0.006 & 0.0022 \\
\hline NC 23 & 0.20 & 0.022 & 0.001 & 0.023 & 0.006 & 0.001 & 0.007 & \\
\hline NC 34 & 0.20 & 0.032 & 0.002 & 0.034 & 0.003 & 0.001 & 0.004 & 0.0020 \\
\hline NC 35 & 0.19 & 0.033 & 0.002 & 0.035 & 0.003 & 0.001 & 0.004 & \\
\hline NC 91 & 0.20 & 0.080 & 0.011 & 0.091 & 0.006 & 0.001 & 0.007 & 0.0057 \\
\hline NC 90 & 0.20 & 0.080 & 0.010 & 0.090 & 0.005 & tr. & 0.005 & \\
\hline
\end{tabular}

mined by Nelson-Riley extrapolation function, and it was compared with the standard values of $\mathrm{NbC}$ and $\mathrm{NbN}$ which were measured by X-ray diffractometer.

Direct observation of precipitates in niobiumtreated steels was carried out by using transmission electron microscopy.

The solubility of NbG in austenite was examined by quantitative analysis of acid-soluble niobium and -insoluble niobium in the specimens which were waterquenched after heating at $925^{\circ}$ to $1200^{\circ} \mathrm{C}$ for 1 to $6 \mathrm{hr}$ and dissolved in $6 \mathrm{~N}-\mathrm{HCl}$ by sodium sulfite-tannin separating extinction method.

\section{Results and Discussion}

\section{Precipitate in Niobium-Treated Steel and the Solubility in Austenite}

The chemical analyses of steels of as-cast state (Table 1) showed that almost all niobium added was in the state of solid solution. Considering from the quantity of $\mathrm{O}$ and $\mathrm{N}_{\text {insol }}, \mathrm{Nb}_{\text {insol }}$ may consist not only of carbide but also of nitride or of oxide. Its quantity, however, was only small. So, it may be conceived that almost all niobium added did not precipitate as acid-insoluble compound (possibly carbide) because of rapid cooling rate of casting. The chemical analyses of steels after hot-rolling showed less than $0.001 \%$ of $\mathrm{Nb}_{\text {sol }}$, indicating that dissolved niobium has precipitated.

According to X-ray diffraction analysis, the crystal structure of precipitate in specimen NC91 was fcc, the lattice parameter $a$ being $4.45_{7} \AA$. Pure $\mathrm{NbC}$ and $\mathrm{NbN}$ of standard specimens have also fcc structure and their lattice parameters were $4.46_{8} \AA$ and $4.38_{4} \AA$, respectively. Since it is well known that both NbC and $\mathrm{NbN}$ are of the structure of $\mathrm{NaCl}$ type and form continuous series of solid solution, it may be concluded that the precipitate in specimen NC91 is NbC containing a small amount of nitrogen.

It is of great importance to examine the solubility of niobium compounds in austenite or in ferrite, in order to clarify the precipitation behavior in niobiumtreated steel. In particular, the solubility in austenite range under condition of practical heat treatment is an important information for presuming the behavior of niobium.

From this point of view, the quantitative analysis of niobium was carried out by separating niobium into the acid-soluble and the acid-insoluble type with specimens which were subjected to heat treatment under the same condition as those used for the measurements of the strength and the grain size. The solubility product of $\mathrm{NbC}$ in austenite was calculated from the data of soaking into austenite for $6 \mathrm{hr}$. When it is assumed that the reaction, $\langle\mathrm{NbC}\rangle=\left(\mathrm{Nb}_{\gamma}\right)+\left(\mathrm{C}_{\gamma}\right)$, reaches the equilibrium and the equilibrium constant of reaction $\mathrm{K}_{\gamma}$ is represented as $\mathrm{K}_{\gamma}=\left[\% \mathrm{Nb}_{\gamma}\right]\left[\% \mathrm{G}_{\gamma}\right]$, then $\log \mathrm{K}_{\gamma}=-14000 / \mathrm{T}+7.58$. This result, however, might involve an assumed value, as it is considered that the reaction could not have reached a perfect equilibrium in the case of low temperatures even if the soaking time was $6 \mathrm{hr}^{4}$ )

Figure 1 shows the result together with some other data. ${ }^{11-16)}$ As seen in the figure, the result of the present work is shown as a straight line which is in the middle position and has a slightly greater inclination as compared with those of other works. From this result, the amount of niobium dissolved in austenite is calculated to be about $0.06 \%$ at $1200{ }^{\circ} \mathrm{C}$ and only $0.002 \%$ at $1000{ }^{\circ} \mathrm{C}$ in the case of niobium-treated $0.2 \%$ carbon steel. It has been ascertained that the amount of niobium dissolved in austenite is very small at low temperatures by considering that there is little possibility of being soaked for more than $6 \mathrm{hr}$ by actual heat treatment.

The analysis of specimens soaked for $1 \mathrm{hr}$ showed the dissolved niobium of about $0.03 \%$ at $1200^{\circ} \mathrm{C}$. Little is known about diffusion of niobium in iron in the austenite and the ferrite range, but it can be assumed that the diffusion rate of niobium in steels in the 


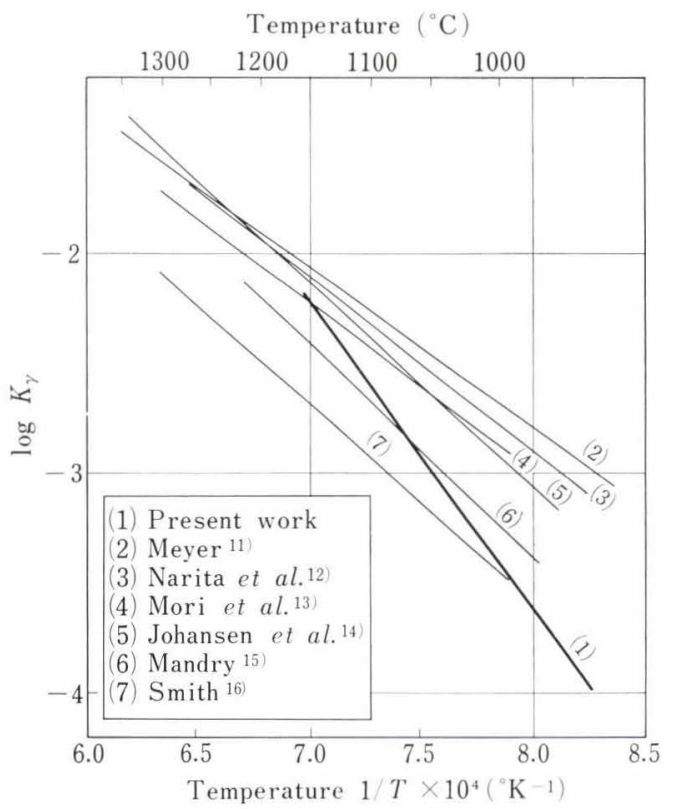

Fig. 1. Solubility products of niobium carbide in austenite

austenite range may be fairly low because of the considerably small dissolving rate of $\mathrm{NbC}$.

\section{Precipitation and Coagulation of $\mathrm{NbC}$ in Austenite and Ferrite}

Thin plates of specimens NC25 and NC91 were annealed or normalized at $925^{\circ}$ to $1200^{\circ} \mathrm{C}$, and the micro-structures were examined by transmission electron microscopy. The results were as follows. Precipitates of indefinite shape, about 400 to $800 \mathrm{~A}$ in size, were dispersed in specimens annealed or normalized at $925^{\circ} \mathrm{C}$, and at higher austenitizing temperatures these precipitates coagulated and grew up and turned into polygonal shape with distinct contour, e.g. of about 500 to $2000 \mathrm{~A}$ in size after treating at $1100^{\circ} \mathrm{C}$. On the other hand, fine precipitates of the size of about $100 \mathrm{~A}$ were seen in addition to these large precipitates when annealed at higher temperatures than $1100^{\circ} \mathrm{C}$. In particular, almost all precipitates in specimen NC25 annealed at $1200^{\circ} \mathrm{C}$ were fine, being about $80 \mathrm{~A}$ in size and dispersed rather plentifully. These fine precipitates may be coherent with matrix, because of indistinct contour suggesting the presence of coherency strain. A selected area diffraction showed that these precipitates were $\mathrm{NbC}$, as concluded from the result of $\mathrm{X}$-ray diffraction.

Thus, it is evident that $\mathrm{NbC}$ precipitates tend to coagulate and grow up as the austenitizing temperature is elevated but some of them dissolve into the matrix and reprecipitate finely and coherently on cooling.

A further experiment was made to verify the coagulation and the growth of precipitates in ferrite range and its effect on strength. Fine NbC particles were dispersed in specimen NC25 by normalizing at $1200^{\circ} \mathrm{C}$, at which a full solution treatment of $\mathrm{NbC}$ was attained, then the change of micro-Vickers hardness of proeutectoid ferrite was examined when the specimen was tempered at $650^{\circ}$ to $800^{\circ} \mathrm{C}$, and the

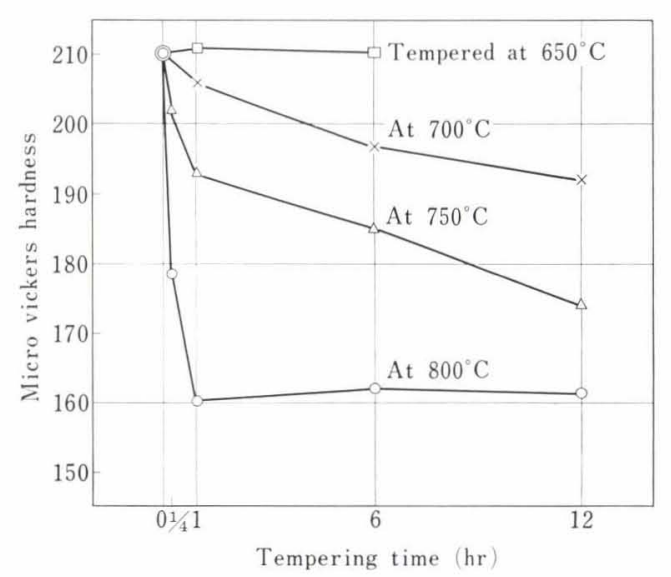

Fig. 2. Effect of tempering on hardness of Nb-treated steel NC25. (6 $\mathrm{mm}$ dia. bar, normalized at $1200^{\circ} \mathrm{C}$ for $1 \mathrm{hr}$ and tempered)

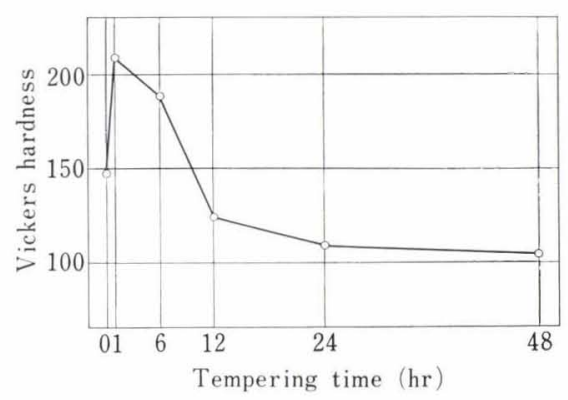

Fig. 3. Effect of tempering at $700^{\circ} \mathrm{C}$ on hardness of $\mathrm{Nb}$ treated steel NC25. (0.15 mm plate, normalized at $1200^{\circ} \mathrm{C}$ for $1 \mathrm{hr}$ and tempered)

relation to the change of precipitation of $\mathrm{NbC}$ was studied.

Figure 2 shows the change of hardness of ferrite grains by tempering of $6 \mathrm{~mm}^{\phi}$ specimens. As seen in the figure, when tempered at $800^{\circ} \mathrm{C}$ the hardness falls suddenly within $\mathrm{l} \mathrm{hr}$, but in the case of $700^{\circ} \mathrm{C}$ or $750^{\circ} \mathrm{C}$ it falls gradually with the tempering time. As $A_{3}$ point of this steel is $850^{\circ} \mathrm{C}$ and $A_{1}$ point is $718^{\circ} \mathrm{C}$, it is obvious that a certain amount of austenite exists in the specimens tempered at $750^{\circ}$ and $800^{\circ} \mathrm{C}$. Then, it may be concluded that the strength of these specimens depends on the change of the state of precipitate such as coagulation and growth during tempering, due to very small solubility of $\mathrm{NbC}$ in austenite or in ferrite. On the other hand, it is presumed that the fall of hardness in the case of tempering at $700^{\circ} \mathrm{C}$ may be due only to the change of the state of precipitate in the ferrite range.

Therefore, the relationship between the change of hardness and the appearance of precipitation was examined by transmission electron microscopy with thin foil of the same specimen after tempering at $700^{\circ} \mathrm{C}$. Figure 3 shows the change of hardness and Photo. 1 shows some examples of observed structures. A little difference between the hardness values shown in Figs. 2 and 3 is due to that between the cooling rates which comes from the different shapes of the specimens. Any distinct precipitate could not be found out in normal- 


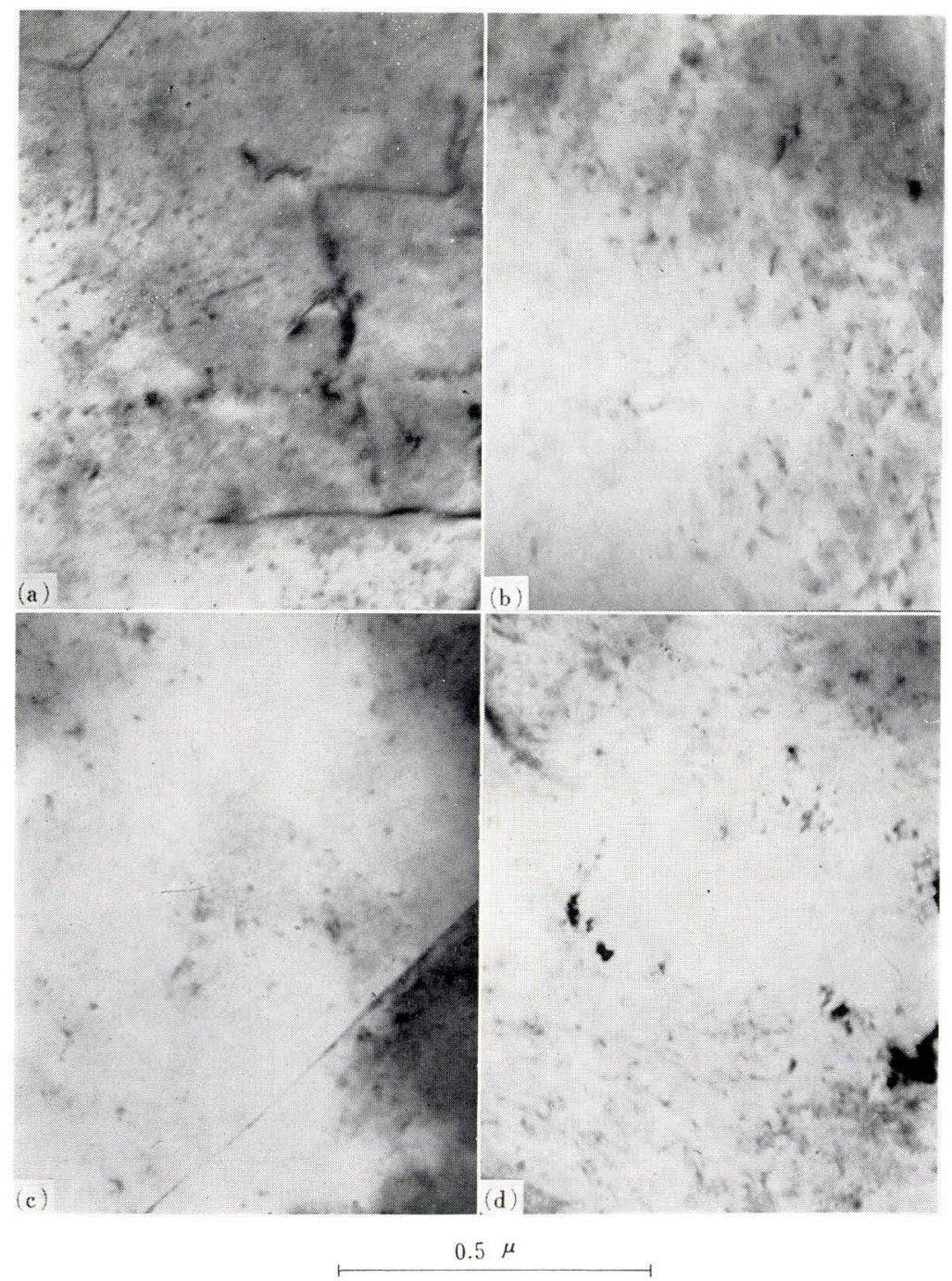

Photo. 1.

Microstructures of Nb-treated steel NC25 normalized at $1200^{\circ} \mathrm{C}$ and tempered at $700^{\circ} \mathrm{C}$ for $1 \mathrm{hr}$ (a), $6 \mathrm{hr}$ (b), $12 \mathrm{hr}$ (c), and $24 \mathrm{hr}$ (d) (thin film) ized specimen. On the other hand, many fine coherent precipitates, being about $50 \mathrm{~A}$ in size and having indistinct contour, were observed in the specimen tempered for $1 \mathrm{hr}$, which showed second hardening as seen from Fig. 3. Also, after the tempering of $6 \mathrm{hr}$, rather distinct $\mathrm{NbC}$ precipitates of 50 to $100 \mathrm{~A}$ in size were seen and in the case of $12 \mathrm{hr}$ they coagulated into the size of 120 to $200 \mathrm{~A}$.

The decrease in hardness may be qualitatively due to the decrease in frictional and/or arresting stress for moving dislocations with the vanishing of coherent stress and with the increase in interparticle distance of precipitates by coagulation and growth. However, it was difficult to clarify the quantitative relationship between the strength and the distribution of $\mathrm{NbC}$ precipitates, for microscopically the dispersion of $\mathrm{NbC}$ was not uniform.

The precipitation behavior of $\mathrm{NbC}$ at continuous cooling has not been known because it was difficult to set up cooling rate accurately over the wide range. Therefore, in the present study, the precipitation behavior, the degree of $\mathrm{NbC}$ precipitation in austenite and in ferrite and the contribution to the strength were examined by setting the cooling rate accurately.

Figure 4 shows the estimated quantity of $\mathrm{NbC}$

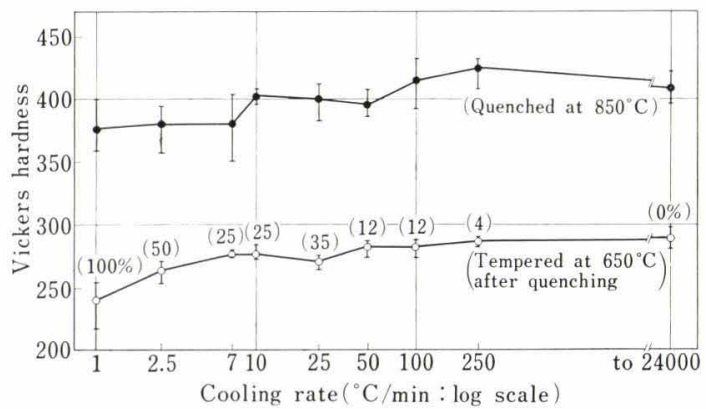

Fig. 4. Effect of cooling rate on hardness of Nb-treated steel NC90 continuously cooled from $1250^{\circ}$ to $850^{\circ} \mathrm{C}$, then quenched, and tempered at $650^{\circ} \mathrm{C}$ for $1 \mathrm{hr}$. (Numerals signify the estimated percent of the quality of NbC precipitated in austenite)

precipitate in austenite when the specimens were continuously cooled from $1250^{\circ}$ to $850^{\circ} \mathrm{C}$ at various cooling rates. Provided the increase in hardness caused by reprecipitation of $\mathrm{NbC}$ during tempering is proportional to the quantity of niobium dissolved before tempering, the percentage of the quantity of niobium dissolved in each specimen the cooling rate of which varies can be calculated from the increase in 
hardness by tempering, as it may be considered that all niobium has precipitated in austenite at the lowest cooling rate $\left(1^{\circ} \mathrm{C} / \mathrm{min}\right)$, and that it has not precipitated at all at the highest cooling rate (quenching). Accordingly, the ratio of the quantity of precipitate in austenite may be presumed inversely. Numerals in Fig. 4 signify the estimated percentage of the quantity of $\mathrm{NbC}$ precipitated in austenite; it is evident that $\mathrm{NbC}$ precipitates even in austenite range though the quantity may be small. For example, only $50 \%$ of niobium added may precipitate in the case of slow cooling such as $2.5^{\circ} \mathrm{C} / \mathrm{min}, 25$ to $30 \%$ in the case of 7 to $25^{\circ} \mathrm{C} / \mathrm{min}$, and about $10 \%$ in the case of 50 to $100^{\circ} \mathrm{C} / \mathrm{min}$. It would be appropriate to say that the quantity of $\mathrm{NbC}$ precipitated in austenite was only a little and the precipitating rate was fairly low even in annealing treatment (average cooling rate of about $100^{\circ} \mathrm{C} / \mathrm{min}$ ) in the present work.

It is not easy to examine strictly the degree of precipitation strengthening in austenite range, even if it can be presumed by hardness at a quenched state, because the results of measurement are fairly scattered as seen in the figure. In the case of slow cooling, the hardness is lower despite a large amount of precipitate, which may be explained as the consequence of the coagulation of precipitates, because the decrease in strength of the matrix (martensite) due to the decrease of carbon content by precipitation of $\mathrm{NbC}$ (below about $0.01 \% \mathrm{C}$ ) may be small. At the cooling rate above $10^{\circ} \mathrm{C} / \mathrm{min}$, it is observed that the hardness increases, which may be due to precipitation strengthening but its degree is not so immense. Also, at the rate above $100^{\circ} \mathrm{C} / \mathrm{min}$ the hardness still rises despite little precipitation; this may relate to the structure, which is, however, not clear.

After all, it may be concluded that $\mathrm{NbC}$ precipitates even in austenite range during continuous cooling, but that the quantity is only small, and the contribution to strengthening is small in practical heat-treatment because of its slow cooling rate. Therefore, the precipitation strengthening in niobium-treated steels may be due to fine $\mathrm{NbC}$ particles which coherently precipitate at temperatures below $\mathrm{A}_{3}$ point.

\section{Grain Size of Austenite and Ferrite}

The grain size of austenite in specimens which were austenitized at $925^{\circ}$ to $1150^{\circ} \mathrm{C}$ for $15 \mathrm{~min}, 1$ and $6 \mathrm{hr}$ and that of ferrite in the same specimens after cooling were measured. As a part of the results, Fig. 5 shows the variations of austenite grain size after heating for $1 \mathrm{hr}$ and of ferrite grain size after normalizing or annealing with the variation of austenitizing temperature. In carbon steel FC22, the austenite grain is as fine as the grain size number $\mathcal{N}=7$ to 8 when the steel is austenitized at $925^{\circ} \mathrm{C}$ for $15 \mathrm{~min}$ to $6 \mathrm{hr}$, but it coarsens suddenly with the increase of austenitizing temperature, that is, $\mathcal{N}=2$ to 3 at $1000^{\circ} \mathrm{C}$ and $\mathcal{N}=$ 1 to -1 at $1100^{\circ} \mathrm{C}$. In niobium-treated steels, on the other hand, the austenite grain is prevented from coarsening up to $1050^{\circ}$ to $1100^{\circ} \mathrm{C}$ in the heating for $\mathrm{l} \mathrm{hr}$, and even in the case of $6 \mathrm{hr}$ they keep to have

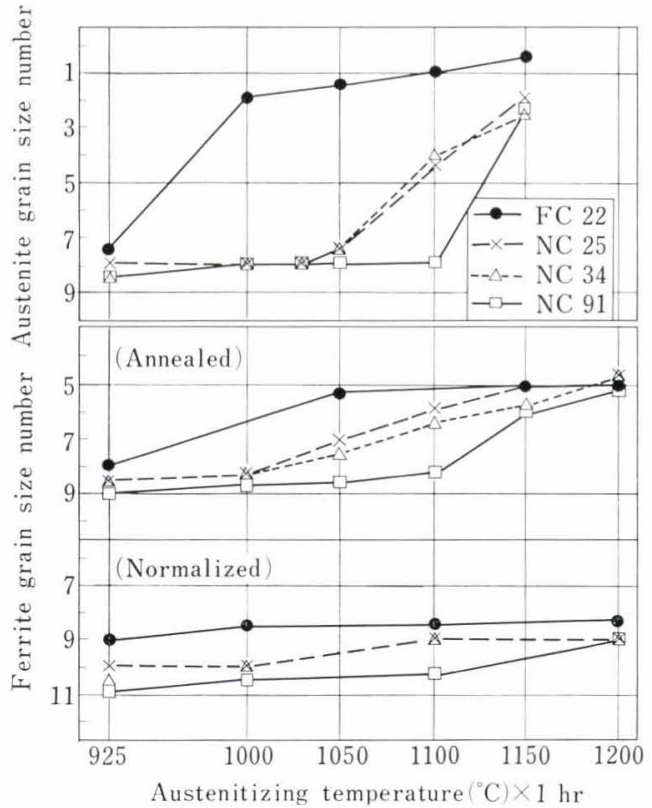

Fig. 5. Effect of austenitizing temperature on austenite grain size and ferrite grain size of carbon steel and $\mathrm{Nb}$ treated steels

fine grains up to $1030^{\circ} \mathrm{C}$, number $\mathcal{N}$ being 7.5 to 9 . The grain-coarsening temperature, at which $\mathcal{N}=5$ in the case of heating for $6 \mathrm{hr}$, was as follows : $955^{\circ} \mathrm{C}$ in specimen $\mathrm{FC} 22,1040^{\circ} \mathrm{C}$ in NC25 and NC34, and $1080^{\circ} \mathrm{C}$ in NC91.

These experimental results show that the addition of a small amount of niobium remarkably refines austenite grain and raises the grain coarsening temperature by $85^{\circ}$ to $125^{\circ} \mathrm{C}$.

In niobium-treated steels, NbC particles precipitated may be most effective to prevent the grain from coarsening; in other words, NbC particles which remain steadily even at fairly elevated temperatures due to small solubility and low dissolving rate in austenite retard the movement of grain boundaries. Also it is suggested that the grain-coarsening temperature increases with increasing niobium content, because the more the quantity of niobium the higher the complete solution temperature of $\mathrm{NbC}$ is.

When the steel is normalized or annealed after austenitizing treatment, the ferrite grain size is substantially controlled by the original austenite grain size. But the carbon steel is apt to have acicular ferrite structure when the austenitizing temperature becomes high, and so the ferrite grain does not coarsen so much as the austenite grain does. On the other hand, niobium-treated steels exhibit little coarsening of ferrite grain, even with austenitizing temperatures, and their grain sizes depend upon niobium content.

In consequence, it is confirmed that the addition of a small amount of niobium is very effective for grain refining and for preventing austenite and ferrite grain from coarsening by the presence of $\mathrm{NbC}$ precipitates.

\section{Strength of Niobium-Treated Steels}

Tensile test and hardness measurement were carried out with specimens of various grain-sizes and disper- 


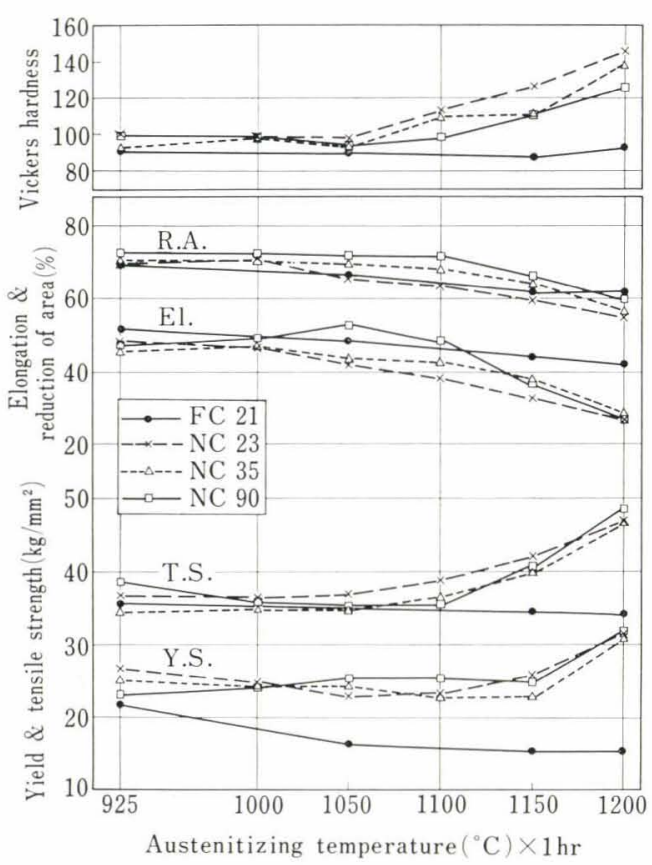

Fig. 6. Mechanical properties of annealed carbon steel and Nb-treated steels

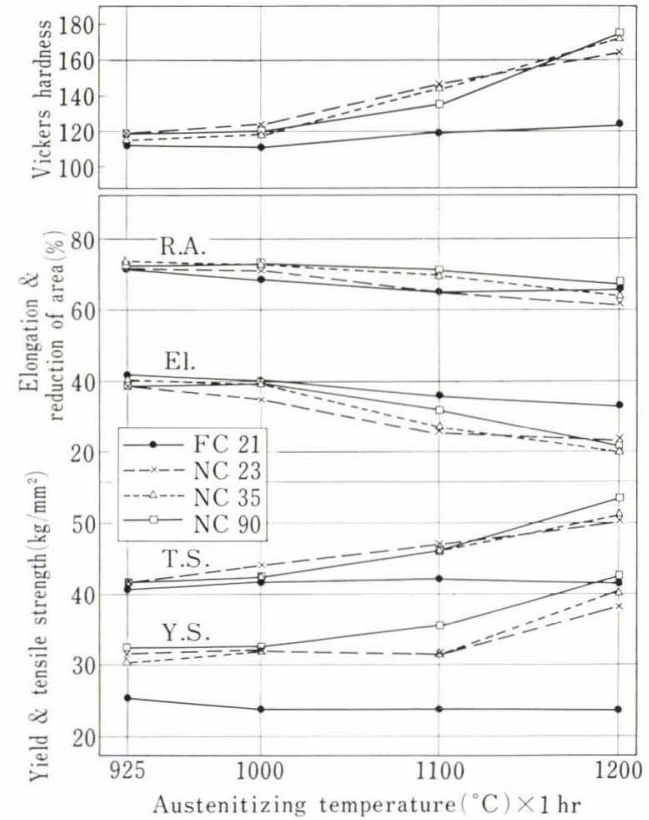

Fig. 7. Mechanical properties of normalized carbon steel and Nb-treated steels

sions of $\mathrm{NbC}$ precipitates obtained by various austenitizing temperatures and cooling rates.

Figures 6 and 7 show the results of annelaed and normalized specimens, respecitvely. As seen in the figures the yield strength of carbon steel FC21 decreases gradually with the increase of austenitizing temperature, and it is considered that this decrease is due simply to coarsening of ferrite grain as seen in Fig. 5. In the case of niobium-treated steels, the yield strength keeps at about the same level despite the grain growth with increasing temperature up to $1150^{\circ} \mathrm{C}$, and that at $1200^{\circ} \mathrm{C}$ increases contrary to the case of carbon steel.

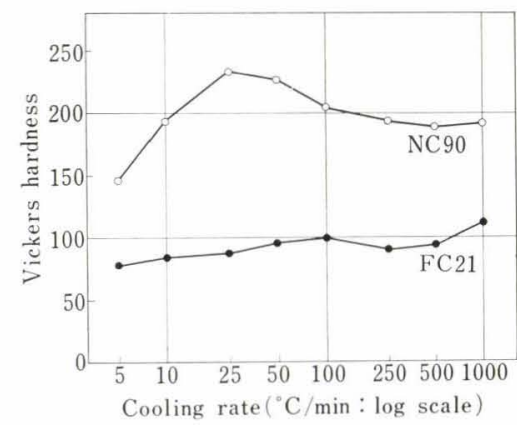

Fig. 8. Effect of cooling rate on hardness of carbon steel FC21 and Nb-treated steel NC90 continuously cooled from $1250^{\circ} \mathrm{C}$ to room temperature

Therefore, it can be said that the degree of strengthening by niobium-treatment increases with the increase of austenitizing temperature. Especially the strengthening at $1200^{\circ} \mathrm{C}$ is remarkable, the yield strength being increased by 14 to $18 \mathrm{~kg} / \mathrm{mm}^{2}$ by niobium treatment. The tensile strength and the hardness below $1050^{\circ} \mathrm{C}$ are not increased by niobium-treatment, but in the case of $1200^{\circ} \mathrm{C}$ the increase of tensile strength is 10 to $14 \mathrm{~kg} / \mathrm{mm}^{2}$ and that of Vickers hardness is 33 to 53. The elongation and the reduction of area of niobium-treated steels shows no great difference from that of the carbon steel.

Remarkable strengthening by niobium-treatment observed in specimens annealed or normalized at elevated temperatures may be caused by reprecipitation of fine NbC particles during cooling as seen by electron microscopy.

In Figs. 6 and 7, the difference in strength by niobium content is little; this suggests that the quantity of niobium dissolved into austenite, which will reprecipitate as fine $\mathrm{NbC}$ particles, is almost the same when steels are austenitized for $1 \mathrm{hr}$ because of its small solubility and low dissolving rate, as far as coarse precipitates may not be effective for precipitation strengthening. These strengthening effects will be discussed in detail in the next paragraph.

When niobium-treated steel is cooled very slowly at the rate of $50^{\circ} \mathrm{C} / \mathrm{hr}$ from elevated temperatures such as $1100^{\circ}$ to $1350^{\circ} \mathrm{C}$, the strength becomes low because of grain coarsening and coagulation of $\mathrm{NbC}$ particles, and the effect of niobium-treatment is only minor.

Further experiments were made to examine the effect of cooling rate on strength more extensively. Hardness values of carbon steel and niobium-treated steel continuously cooled to room temperature after full solution treatment at $1250^{\circ} \mathrm{C}$ were measured. Figure 8 shows the results. The hardness of carbon steel decreases at slow cooling rates by grain coarsening and increases at rapid cooling rates by refining of structure such as the formation of acicular ferrite. In niobium-treated steel NC90, on the contrary, the maximum value in hardness is observed at cooling rate of $25^{\circ} \mathrm{C} / \mathrm{min}$. Low hardness at slower cooling rates than $25^{\circ} \mathrm{C} / \mathrm{min}$ may be caused by grain coarsening, coagulation of precipitates, and decrease of $\mathrm{NbC}$ precipitated in ferrite due to the precipitation in austenite 
range. The decrease in hardness of NC90 at higher cooling rates may be due simply to the decrease of effective precipitation. Thus, the hardness of niobium treated steel is about three times as high as that of carbon steel even in the case of a rather slow cooling rate such as $25^{\circ} \mathrm{C} / \mathrm{min}$, which is worth noticing.

\section{Effect of Grain Size and Precipitation on Yield Strength}

As generally known, lower yield strength, $\sigma_{y}$, and grain diameter, $d$, follow the Hall-Petch relation :

$$
\sigma_{y}=\sigma_{o}+k_{y} d^{-1 / 2}
$$

where $\sigma_{o}$ is frictional stress to moving dislocations and equivalent to the yield strength of single crystal. According to Conrad, ${ }^{17)} \sigma_{o}$ consists of thermal component $\sigma^{*}$ and athermal component $\sigma_{\mu}$, and consequently,

$$
\sigma_{y}=\sigma^{*}(T, \dot{\varepsilon})+\sigma_{\mu}+k_{y} d^{-1 / 2}
$$

where $\sigma^{*}$ depends on temperature $\mathcal{T}$, composition, strain, and strain rate $\dot{\varepsilon}$, and $\sigma_{\mu}$ depends on distribution of dislocation, $\mathrm{C}+\mathrm{N}$ in solution, and precipitates, etc., and is proportional to the shear modulus $\mu$.

In Fig. 9, the variation of yield strength with average grain diameter of ferrite is shown to examine the validity of these relations in the present case. In carbon steel FC21, the validity of Hall-Petch relation is observed. In the case of niobium-treated steels the relationship between $\sigma_{y}$ and $d$ at the same cooling rate is independent of niobium content, and $\sigma_{y}$ much increases at lower value of $d^{-1 / 2}$ (it corresponds to large grain size, austenitized at elevated temperatures).

It has been observed that the yield strength of some precipitation-strengthened materials does not always fit the Hall-Petch relation ${ }^{18), 19)}$; this has been explained to be due mainly to an increase of frictional stress $\sigma_{o}$ by the precipitates in grain. When the effects of precipitation and grain refining are assumed to be additive to each other, the Conrad relation is considered as reasonable in this case. Therefore, from this point of view, the following consideration was tried to confirm the effects of niobium-treatment.

The difference in yield strength between niobiumtreated steel and carbon steel, both being subjected to the same heat-treatment, shows the degree of strengthening by niobium-treatment, $\Delta \sigma_{y}$, and the difference when the grain size is the same with each other shows the strengthening by precipitation, $\Delta \sigma_{y p}$; hence, $\Delta \sigma_{y}-\Delta \sigma_{y p}=\Delta \sigma_{y G}$, which signifies strengthening by grain refining. In Fig. 10, an example of the result of normalized specimen calculated from Fig. 9 is shown. As seen in this figure, it is apparent that the precipitation strengthening, $\Delta \sigma_{y p}$, increases gradually with the increase of austenitizing temperature, and that almost all increase in yield strength at elevated temperatures is due to this strengthening. The degree of these strengthening coincides with the quantity of niobium dissolved into austenite just before normalizing (Fig. 11). Therefore, it is evident that the reprecipitation of NbC during cooling contributes mainly to strengthening of specimens which have been treated at elevated

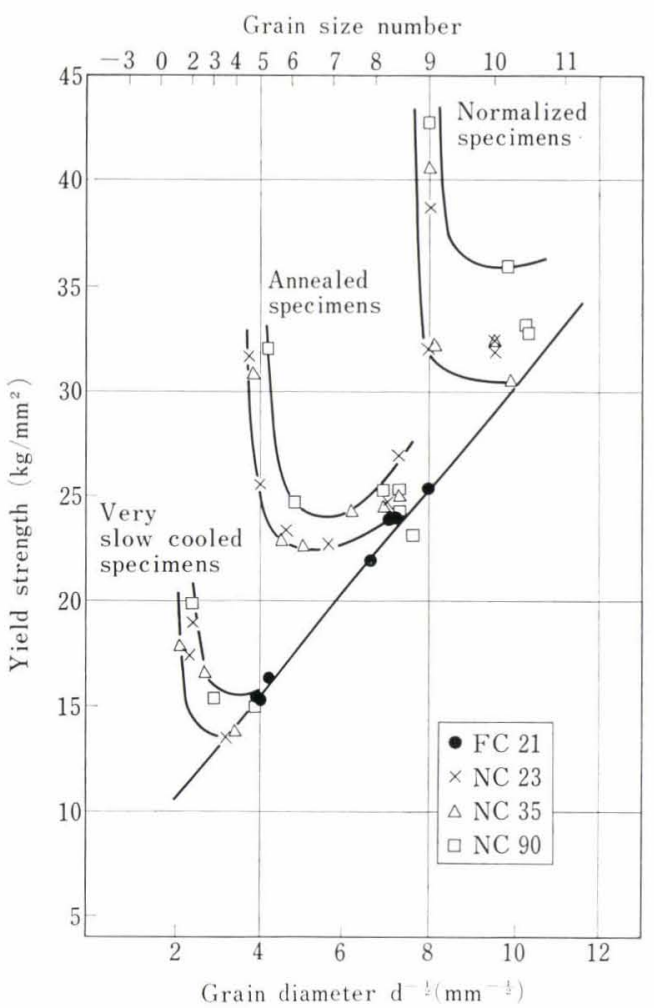

Fig. 9. Relation between yield strength and ferrite grain size

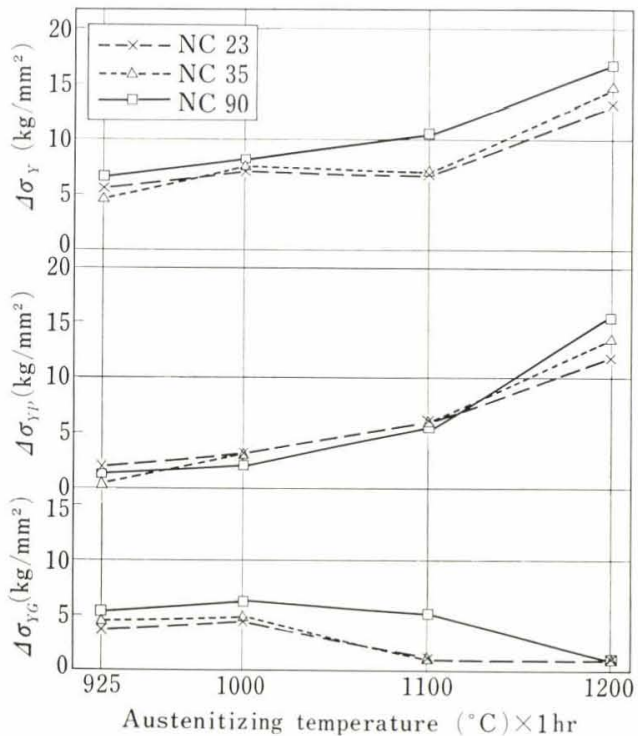

Fig. 10. Increments of yield strength, $\Delta \sigma_{y}, \Delta \sigma_{y p}$, and $\Delta \sigma_{y G}$ of normalized Nb-treated steels at various austenitizing temperatures

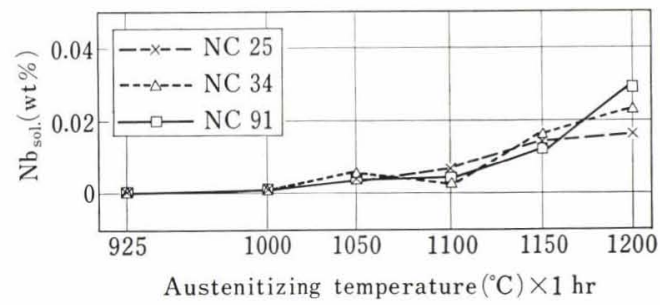

Fig. 11. Acid-soluble $\mathrm{Nb}$ content in Nb-treated steels quenched at various austenitizing temperatures 
temperatures. On the other hand, the strengthening by the treatment at low temperatures is due mainly to grain refinement but its degree is less than that due to precipitation. The tendency of the change of $\Delta \sigma_{y G}$ with austenitizing temperature agrees with that of ferrite grain size (Fig. 5).

In annealed specimens, there is also a similar relation as mentioned above. In either case, it is confirmed that the strengthening by niobium-treatment is due mainly to grain refinement when the steels are austenitized below about $1050^{\circ} \mathrm{C}$ and due mainly to $\mathrm{NbC}$ precipitation when treated above $1050^{\circ} \mathrm{C}$.

Thus, the causes of strengthening of niobium-treated steel, could be clarified, but the assumptions that the Hall-Petch or the Conrad relation is applicable to the materials including the fine precipitates such as $\mathrm{NbC}$, and that both effects of the precipitation and the grain refining on the strengthening are additive to each other may not exactly explain the fact, so far as these relations are of restricted validity and not sufficiently characterized yet on the basis of dislocation theory. Accordingly, a further investigation is desirable to confirm the problem in detail with suitable specimens and experimental procedures.

\section{Summary}

The precipitation behavior of NbC in steels and the changes of grain size and strength by various heattreatments were examined with $0.2 \%$ carbon steels containing 0.02 to $0.09 \%$ niobium, and the effects of grain refining and $\mathrm{NbC}$ precipitation on the strength of niobium-treated steels were discussed. The results may be summarized as follows.

(1) The solubility of NbC (fcc structure, the lattice parameter $a=4.45_{7}$ A) in austenite is small and the solubility product of $\mathrm{NbC}$ in the temperature range of $925^{\circ}$ to $1150^{\circ} \mathrm{C}$ is assumed as

$$
\log \left[\% \mathrm{Nb}_{\gamma}\right]\left[\% \mathrm{C}_{\gamma}\right]=-14000 / T+7.58
$$

(2) Though NbC particles precipitated tend to coagulate with the increase of austenitizing temperature, they remain in steel and prevent austenite grain from coarsening because of its small solubility and low dissolving rate.

(3) The highest strength is obtained when the cooling rate from austenitizing temperature to room temperature is $25^{\circ} \mathrm{C} / \mathrm{min}$. When niobium-treated steel is continuously cooled after full solution treatment, NbC precipitates not only at lower temperatures than $\mathrm{A}_{3}$ point but also at the temperatures of austenite range, and the precipitation from austenite will cause less strengthening effect than that from ferrite because of less quantity of effective precipitates. The strengthening may be due mainly to fine coherent precipitates formed at lower temperatures than $\mathrm{A}_{3}$ point.

(4) Finely dispersed coherent $\mathrm{NbC}$ precipitates may lost coherency with matrix and coagulate by reheating at temperatures of ferrite range above $700^{\circ} \mathrm{C}$, and the hardness of steel decreases. The dispersion of $\mathrm{NbC}$ is not microscopically so uniform as to clarify the precipitation strengthening quantitatively.

(5) Strengthening effects by niobium-treatment may be explained on the assumption that both effects of the grain refinement and the fine $\mathrm{NbC}$ precipitation are additive to each other. An increase in strength is due mainly to refining of ferrite grain when the steels are austenitized at lower temperatures than about $1050^{\circ} \mathrm{C}$, and due mainly to fine $\mathrm{NbC}$ precipitation when treated at higher temperatures.

\section{REFERENCES}

1) F. W. Starratt: J. Metals, 10 (1958), 799.

2) F. E. Vanvoris: Metal Prog., 82 (1962), 84.

3) K. Narita and A. Miyamoto: Tetsu-to-Hagané, 50 (1964), 174 .

4) W. B. Morrison: J. Iron Steel Inst., 201 (1963), 317.

5) K. J. Irvine: J. Iron Steel Inst., 201 (1963), 944.

6) J. M. Gray, D. Webster, and J. H. Woodhead: J. Iron Steel Inst., 203 (1965), 812.

7) M. Tanino: Tetsu-to-Hagané, 52 (1966), 794.

8) Y. Imai and T. Masumoto: Tekko to Gokin Genso (1965), 723, Seibundo, Tokyo.

9) Y. Imai and Y. Shōno: Bulletin Japan Inst. Metals, 5 (1966), 762.

10) Y. Imai and H. Hirotani: Tetsu-to-Hagané, 44 (1958), 480.

11) L. Meyer: Z. Metallk., 58 (1967), 396.

12) K. Narita and S. Koyama: Tetsu-to-Hagané, 52 (1966), 789.

13) T. Mori, M. Tokizane, Y. Nakazima, and T. Saheki: Tetsu-to-Hagané., 51 (1965), 2031.

14) T. H. Johanson, N. Christensen, and B. Augland: Trans. AIME, 239 (1967), 1651.

15) P. Mandry: Métaux Corrosion Industrie, 43 (1967), 389; 44 (1968), 24.

16) R. P. Smith: Trans. AIME, 236 (1966), 220.

17) H. Conrad: Iron and its Dilute Solid Solutions, (1963), 315, John Wiley \& Sons, New York.

18) W. B. Morrison and J. H. Woodhead: J. Iron Steel Inst., 201 (1963), 43

19) A. Suzuki, T. Kaneda, E. Niina, and H. Kazi : Tetsu-toHagané, 50 (1964), 2014. 